\title{
Ultrastructure of pedal muscle as a function of temperature in nacellid limpets
}

\author{
Glenn Lurman · Till Blaser • Miles Lamare • \\ Koh-Siang Tan $\cdot$ Hans Poertner $\cdot$ \\ Lloyd S. Peck $\cdot$ Simon A. Morley
}

Received: 16 December 2009 / Accepted: 2 April 2010 / Published online: 18 April 2010

(C) Springer-Verlag 2010

\begin{abstract}
Temperature and mitochondrial plasticity are well studied in fishes, but little is known about this relationship in invertebrates. The effects of habitat temperature on mitochondrial ultrastructure were examined in three confamilial limpets from the Antarctic (Nacella concinna), New Zealand (Cellana ornata), and Singapore (Cellana radiata). The effects of seasonal changes in temperature were also examined in winter and summer $C$. ornata. Stereological methods showed that limpet pedal myocytes were $1-2$ orders of magnitude smaller in diameter $(\approx 3.5 \mu \mathrm{m})$ than in vertebrates, and that the diameter did not vary as a function of temperature. Mitochondrial volume density
\end{abstract}

Communicated by J. P. Grassle.

G. Lurman $(\bowtie) \cdot$ L. S. Peck · S. A. Morley

British Antarctic Survey,

National Environment Research Council, Cambridge, UK

e-mail: glenn.lurman@ ana.unibe.ch

\section{G. Lurman · T. Blaser}

Institut fuer Anatomie der Universitaet Bern,

Bern, Switzerland

G. Lurman $\cdot$ H. Poertner

Alfred-Wegener-Institut fuer Polar und Meeresforschung,

Bremerhaven, Germany

\section{Lamare}

Portobello Marine Lab, University of Otago,

Dunedin, New Zealand

\section{K.-S. Tan}

Tropical Marine Science Institute,

National University of Singapore, Singapore, Singapore
$\left(\mathrm{Vv}_{(\mathrm{mt}, \mathrm{f})}\right)$ was approximately 2-4 times higher in $N$. concinna (0.024) than in the other species (0.01 and 0.006), which were not significantly different from each other. Mitochondrial cristae surface density $\left(\mathrm{Sv}_{(\mathrm{im}, \mathrm{mt})}\right)$ was significantly lower in summer $C$. ornata $\left(24.1 \pm 0.50 \mu \mathrm{m}^{2} \mu \mathrm{m}^{-3}\right)$ than both winter $C$. ornata $\left(32.3 \pm 0.95 \mu \mathrm{m}^{2} \mu \mathrm{m}^{-3}\right)$ and $N$. concinna $\left(34.3 \pm 4.43 \mu \mathrm{m}^{2} \mu \mathrm{m}^{-3}\right)$. The surface area of mitochondrial cristae per unit fibre volume was significantly higher in $N$. concinna, due largely to the greater mitochondrial volume density. These results and previous studies indicate that mitochondrial proliferation in the cold is a common, but not universal response by different species from different thermal habitats. Seasonal temperature decreases on the other hand, leading preferentially to an increase in cristae surface density. Stereological measures also showed that energetic reserves, i.e. lipid droplets and glycogen in the pedal muscle changed greatly with season and species. This was most likely related to gametogenesis and spawning.

\section{Introduction}

The way temperature affects muscle ultrastructure has been the subject of much research and is well characterized in fish (Egginton and Sidell 1989; Sänger 1993; Johnston et al. 1998). Cold adaptation and acclimation generally lead to muscular hypertrophy and increased volume density of mitochondria (Johnston et al. 1998), and in an isolated case, the surface density of mitochondrial cristae (St-Pierre et al. 1998). Two main hypotheses have been proposed to explain why mitochondria proliferate in the cold. Firstly, in some species ATP production capacity and the efficiency of mitochondria are reduced in the cold due in part to increased leakiness of the inner mitochondrial membrane, and as a 
consequence more mitochondria are needed to fuel the energetic demands (Pörtner et al. 2000). Secondly, rates of diffusion are reduced in the cold, such that the delivery of oxygen to the mitochondria and ATP to the sites of energetic demand are diminished. An increase in the number of mitochondria in the tissue supports oxygen diffusion via lipid membranes and brings the mitochondria closer to the site of energetic demand, reducing the diffusion distance (Sidell 1983; Guderley 2004a).

Earlier work compared volume densities and capacities of mitochondria in northern temperate with sub-Arctic marine invertebrates (annelids and molluscs,) and found that the mitochondrial volume density increased as habitat temperature decreased (Sommer and Pörtner 2002). More recent work found that the Antarctic brachiopod, Liothyrella $u v a$, had a significantly higher volume density of mitochondria than their temperate con-generic counterparts from New Zealand, Liothyrella neozelanica. Interestingly, an increase in the surface density of mitochondrial cristae was also revealed in $L$. neozelanica as a result of winter acclimatization (Lurman et al. 2010). This mirrors other findings in the Antarctic limpet, Nacella concinna, where the surface density of mitochondrial cristae decreased as acclimation temperature increased (Morley et al. 2009), although this may not be universal as we have observed in laternulid bivalves (Lurman, unpubl data). Changes in the surface density of mitochondrial cristae would have significant functional effects on the mitochondria as this could lead to increased quantities of mitochondrial enzymes within the mitochondria, thus giving a higher mitochondrial oxidative potential or ATP synthesis capacity per unit volume of mitochondrion.

To better understand the effect that temperature has on mitochondria, a comparison of mitochondrial characteristics was undertaken in a number of con-familial species of limpets from the tropics, temperate waters and the Antarctic. Here we examine plasticity of mitochondria at an ultrastructural level from three different species of patellogastropod limpets in the family Nacellidae: $N$. concinna from the Antarctic; Cellana ornata from New Zealand; and Cellana radiata from Singapore. We hypothesized that we would find an increase in the volume density of mitochondria with decreased habitat temperature, and based on previous findings (Morley et al. 2009; Lurman et al. 2010), an increase in the surface density of mitochondrial cristae in the winter acclimatized $C$. ornata.

For this comparison we elected to use the pedal muscle as this is a large organ and would contribute considerably to the whole limpet respiration rate. However, we are also aware that unlike vertebrate, skeletal or cardiac muscle, the limpet pedal muscle is a multifunctional organ. As well as being responsible for locomotion, the sole is used for the production of mucopolysaccharides, which not only enables locomotion (Voltzow 1994), but can also act as an algal fertilizer (Plagényi and Branch 2000). The pedal muscle in gastropods is also a site where energetic resources such as carbohydrates and lipids are stored (Lawrence 1976; Voltzow 1994). The effects of a number of factors have been examined in relation to these stores, for example, season strongly affects both lipid and carbohydrate stores, being greatest in summer (Barry and Munday 1959; Blackmore 1969; Simpson 1982), although this is due largely to gametogenesis rather than dietary restriction (Lawrence 1976). We also used stereological tools to determine intracellular lipid droplet and glycogen contents in pedal muscle myocytes to gauge any inter-individual variation in tissue energy reserves.

\section{Methods}

Limpet tissue preparation

Limpets, Nacella concinna, Cellana ornata and C. radiata were collected for pedal muscle sampling (see Table 1 for details of collection location and date). The pedal muscle is the functional muscle for activity in all the three species. It was dissected and preserved for the analysis of mitochondrial parameters as in Morley et al. (2009). In brief, the complete pedal muscle was quickly dissected out and cut along the length of the haemocoel into two halves. Both ends of the muscle section were pinned at resting length in a wax dish and immediately immersed in preservative $\left(\sim 800 \mathrm{mOsm} \mathrm{kg}^{-1}: 30.23 \mathrm{~g}\right.$ PIPES acid, $3 \%$ glutaraldehyde, $0.11 \mathrm{~g}$ calcium chloride, $0.05 \mathrm{~g}$ sodium azide, $5 \mathrm{~g}$ sucrose, buffered to $\mathrm{pH} 7.6$ and made up to $500 \mathrm{ml}$ with distilled water). After $3 \mathrm{~h}$, the tissue was transferred to a fresh preservative and held at $+4^{\circ} \mathrm{C}$ overnight before being washed thrice and then stored in PIPES buffer lacking glutaraldehyde. Transverse sections were cut through the midsection of the pedal muscle with a razor blade and then fixed for $2 \mathrm{~h}$ in $4 \%$ osmium ferricyanide. Tissues were washed twice with tap water before bulk staining for $1 \mathrm{~h}$ with $1 \%$ uranyl acetate in $0.05 \mathrm{M}$ maleate buffer ( $\mathrm{pH}$ 5.0). Tissues were then serially dehydrated with ethanol before embedding and curing with Quetol 651 (Ellis 2002). Samples were sectioned (semithin $0.5 \mu \mathrm{m}$, ultrathin $80 \mathrm{~nm}$ ) on a Reichert ultramicrotome.

\section{Morphometry and stereology}

Two blocks were prepared from each limpet. Semi-thin sections $(0.5 \mu \mathrm{m})$ were stained with methylene blue and analysed at $100 \times$ magnification using a Leitz DMRBE light microscope fitted with a digital camera, connected to a computer running cell ${ }^{\mathrm{D}}$ v2.8 (Olympus Soft Imaging 
Table 1 Animal collection details

\begin{tabular}{|c|c|c|c|c|c|c|}
\hline Species $(N)$ & Location & Collection date & $\begin{array}{l}\text { Collection water } \\
\text { temperature }\left({ }^{\circ} \mathrm{C}\right)\end{array}$ & $\begin{array}{l}\text { Shell } \\
\text { length (mm) }\end{array}$ & $\begin{array}{l}\text { Normal habitat } \\
\text { temperature } \\
\text { range }\left({ }^{\circ} \mathrm{C}\right)\end{array}$ & Habitat \\
\hline Nacella concinna (6) & Rothera Station, Antarctica & November 2005 & 0 & $30.0 \pm 1.37$ & -2 to 1 & Shallow subtidal \\
\hline Cellana ornata (8) & Otago Harbour, New Zealand & July 2007 & 7 & $29.4 \pm 0.56$ & 6 to 17 & Lower intertidal \\
\hline Cellana ornata (6) & Otago Harbour, New Zealand & March 2008 & 15 & $28.2 \pm 1.17$ & & Lower intertidal \\
\hline Cellana radiata $(6)$ & Kusu/Lazurus Is, Singapore & June 2007 & 29 & $33.4 \pm 3.28$ & 27 to 31 & Lower intertidal \\
\hline
\end{tabular}

Table 2 Distribution of sub-cellular components within limpet pedal muscle myocytes as a percentage of the pedal muscle volume

\begin{tabular}{llllllll}
\hline & Myofibers $(\%)$ & Collagen $(\%)$ & Glycogen $(\%)$ & Lipid (\%) & Mitochondria (\%) & Nuclear (\%) & Other (\%) \\
\hline N. concinna & $56.8 \pm 5.05$ & $20.9 \pm 2.68$ & $15.9 \pm 7.63^{\mathrm{a}, \mathrm{b}}$ & $0.67 \pm 0.14^{\mathrm{a}}$ & $1.31 \pm 0.12^{\mathrm{a}}$ & $0.99 \pm 0.26$ & $3.40 \pm 0.82$ \\
C. ornata (Winter) & $59.7 \pm 6.09$ & $17.6 \pm 1.52$ & $17.2 \pm 2.98^{\mathrm{a}}$ & $4.20 \pm 0.82^{\mathrm{b}}$ & $0.36 \pm 0.07^{\mathrm{b}}$ & $0.36 \pm 0.13$ & $0.49 \pm 0.21$ \\
C. ornata (Summer) & $68.1 \pm 3.25$ & $26.6 \pm 3.20$ & $1.97 \pm 0.59^{\mathrm{b}}$ & $0.80 \pm 0.19^{\mathrm{a}}$ & $0.66 \pm 0.12^{\mathrm{b}}$ & $0.16 \pm 0.05$ & $1.71 \pm 0.24$ \\
C. radiata & $58.3 \pm 4.08$ & $27.6 \pm 3.54$ & $7.36 \pm 1.54^{\mathrm{a}, \mathrm{b}}$ & $0.22 \pm 0.16^{\mathrm{a}}$ & $0.37 \pm 0.07^{\mathrm{b}}$ & $0.22 \pm 0.07$ & $5.81 \pm 0.93$ \\
\hline
\end{tabular}

Different letters indicate a significant difference. Values in columns without any letters were not significantly different

Solutions GmbH, Germany). Systematic random sampling was accomplished by starting in the top left corner and sampling every fifth frame, with ten frames sampled, i.e. 250 myocytes. The maximum cell diameter $(\mu \mathrm{m})$ was determined as the distance between the two most distant myocyte edges perpendicular to the longitudinal axis of the cell and was measured using the arbitrary distance function.

Ultra-thin sections $(80 \mathrm{~nm})$ were analysed using a Philips EM400 electron microscope. A series of ten pictures was taken at $6,000 \times$ magnification. Systematic random sampling was accomplished by starting in the top left corner and sampling every fifth frame. The relative densities are given either in relation to the entire sampled area, i.e. in relation to whole pedal muscle volume (Table 2), or as a proportion of muscle fibre volume as in the case of mitochondria $\left(\mathrm{Vv}_{(\mathrm{mt}, \mathrm{f})}\right)$. Volume densities were determined using the point counting method (Weibel 1979) with a $0.4 \mu \mathrm{m}$ grid in Image $\mathbf{J}$ such that approximately 12,000 points (i.e. $1.9 \mathrm{~mm}^{2}$ ) were sampled in total. Electron micrographs of individual mitochondria (5-15 individual ${ }^{-1}$ ) at a magnification of $32,000 \times$ were taken for the estimation of the surface density of the inner mitochondrial membrane $\left(\mathrm{Sv}_{(\mathrm{im}, \mathrm{mt})}\right)$ in relation to the volume of the mitochondrion, which was determined using line-intercept measurements (Weibel 1979). Multiplication of $\mathrm{Vv}_{(\mathrm{mt}, \mathrm{f})}$ by the $\mathrm{Sv}_{(\mathrm{im}, \mathrm{mt})}$ gave the surface area of mitochondrial cristae per unit fibre volume (aerobic capacity; $\mathrm{Sv}_{(\mathrm{im}, \mathrm{f})}$ ).

Statistical analysis

Statistical analysis was performed using SigmaStat 3.5. All data were checked for normality using a KolmogorovSmirnov test (with Lilliefor's correction) and equal vari- ances. For data with a Gaussian distribution and equal variances, one-way ANOVAs were used to test for significant species effects, while post hoc Holm-Sidak tests were used to determine significant differences between groups. Gaussian distributed data with unequal variances were tested for significance (without transformation) using a Kruskal-Wallis one-way ANOVA on ranks and for differences between groups using Tukey tests. All values are given as the mean \pm standard error of the mean (SE).

\section{Results}

The mean diameter of the myocytes did not vary significantly among species (ANOVA, $p=0.14, F=5.5, d f=3$ ): $N$. concinna, $3.44 \pm 0.08 \mu \mathrm{m}$; winter $C$. ornata, $3.23 \pm$ $0.25 \mu \mathrm{m}$; summer $C$. ornata, $3.58 \pm 0.09 \mu \mathrm{m}$; $C$. radiata, $3.16 \pm 0.10 \mu \mathrm{m}$. Individual myocytes are wrapped in collagen sheaths with the collagen fibres oriented parallel to the myocytes (Fig. 1) and multiple myocytes are found as collagen-wrapped fibre bundles. The collagen content within the pedal muscle was $18-28 \%$ (Table 2 , ANOVA, $p<0.34$, $F=1.14, d f=3)$ and did not differ among species. The myofiber to collagen ratio did not vary significantly $(\sim 2.8: 1)$, although it was slightly higher for summer C. ornata (3.5:1). Different proportions of various structures in the whole pedal muscle were dominated primarily by the amount of glycogen, which differed significantly amongst the groups (Table 2, Kruskal-Wallis, $p=0.001$, $H=17.7, d f=3$ ). Glycogen made up approximately $16 \%$ of the whole pedal muscle volume in the Antarctic N. concinna, although there was great variation among individuals ranging from 2 to $26 \%$ (Table 2). 


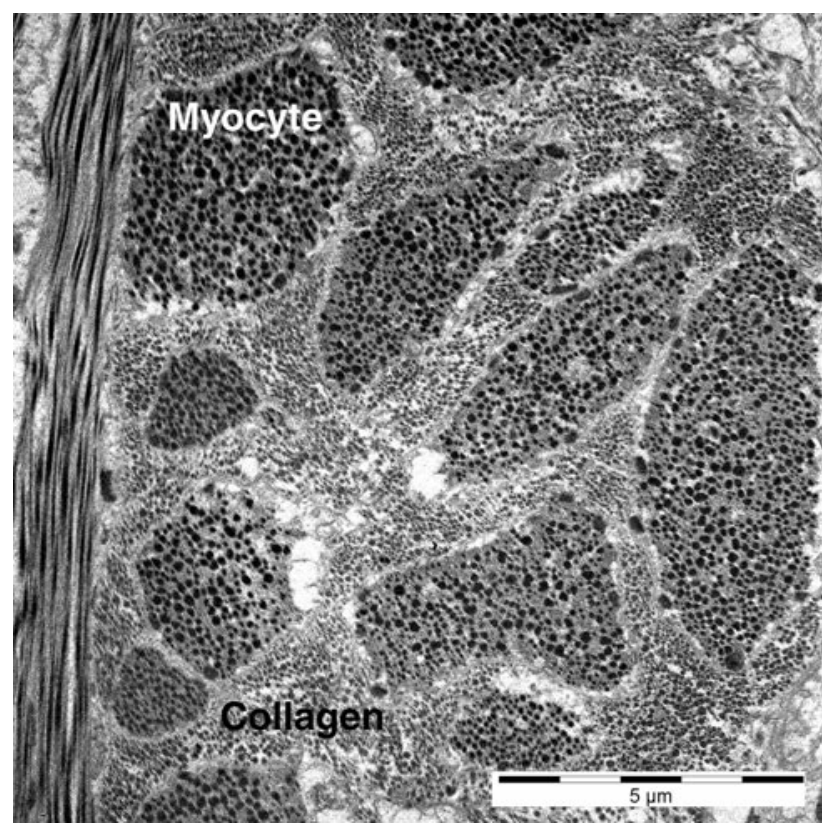

Fig. 1 Electron micrograph showing collagen sheaths around individual myocytes in Cellana radiata pedal muscle. Scale bar represents $5 \mu \mathrm{m}$

Approximately $17 \%$ of the volume of the pedal muscle in winter $C$. ornata consisted of glycogen. On the other hand, $2 \%$ of the pedal muscle volume of summer $C$. ornata and $7 \%$ of the pedal muscle volume of $C$. radiata were taken up by glycogen (Table 2). The relative volume of lipid was low, making up $\sim 4 \%$ at the most of the pedal muscle volume in winter $C$. ornata (Table 2). Nevertheless, this was significantly higher (7-20-fold) than in all other species (Kruskal-Wallis, $p<0.001, H=19.9, d f=3$ ).

The distribution of mitochondria within the myocytes was predominantly (63-84\%) subsarcolemmal. The relative volume density of mitochondria, $\mathrm{Vv}_{(\mathrm{mt}, \mathrm{f})}$, was 2-4 times higher in $N$. concinna (Fig. 2, ANOVA, $p<0.001$, $F=26.0, d f=3)$. There were no significant differences in the volume density of mitochondria between either the two $C$. ornata groups, or $C$. radiata. The relative surface area of cristae, $\mathrm{Sv}_{(\mathrm{im}, \mathrm{mt})}$, was highest in N. concinna, and lowest in the summer $C$. ornata (Fig. 3, Kruskal-Wallis, $p=0.01$, $H=11.3, d f=3$, see also Fig. 4). These two factors combined, known as the surface area of mitochondrial cristae per unit fibre volume (aerobic capacity) was 4-5 times greater in the Antarctic N. concinna, than both winter and summer $C$. ornata, and approximately three times greater than the tropical $C$. radiata (Fig. 5, Kruskal-Wallis, $p=0.005, H=12.9, d f=3)$.

\section{Discussion}

Similar to previous observations in other marine gastropods (Voltzow 1990) including Patella vulgata (Stützel 1984),

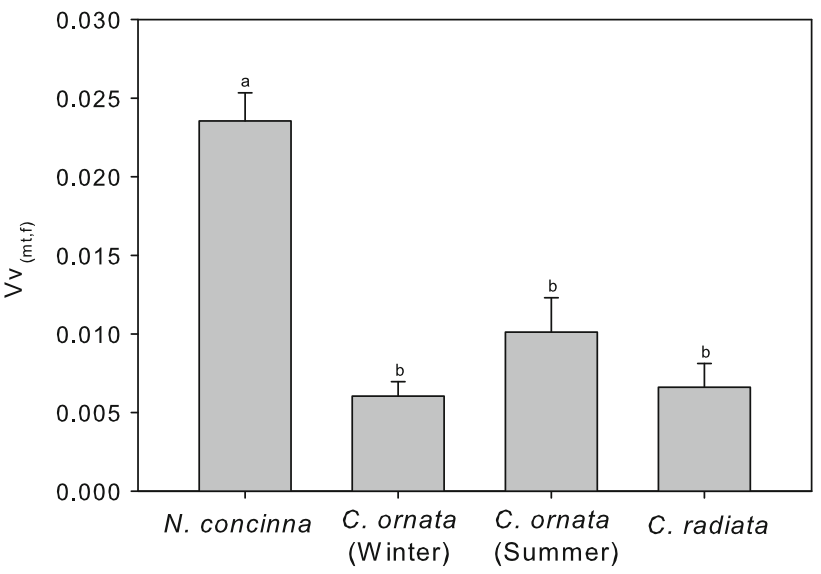

Fig. 2 Mean volume density of mitochondria ( \pm SE) relative to myofiber volume density in pedal muscle of limpets, Nacella concinna, Cellana ornata, and $C$. radiata. Different letters indicate significant differences between groups

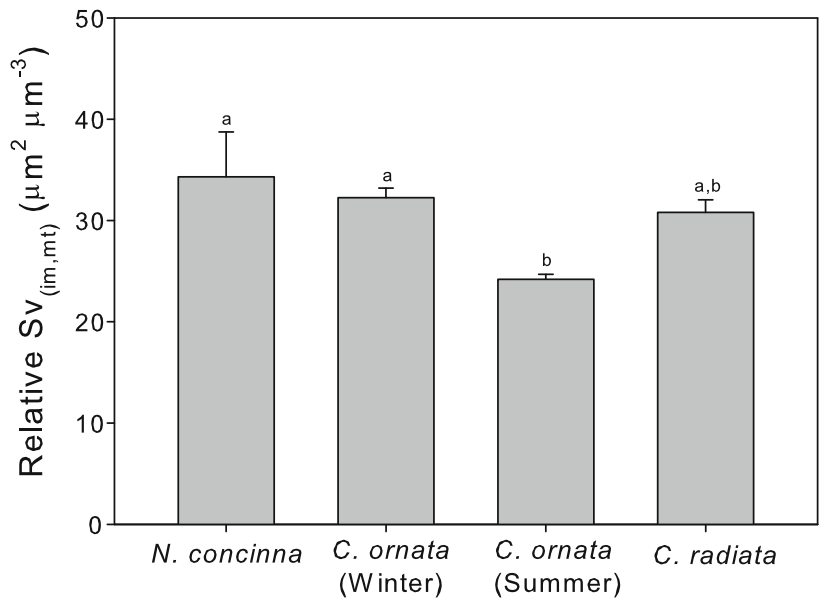

Fig. 3 Surface density of mitochondrial cristae relative to mitochondrial volume in pedal muscle of the limpets, Nacella concinna, Cellana ornata, and Cellana radiata. Values shown are mean \pm SE. Different letters indicate significant differences between the groups

individual myocytes were wrapped in collagen sheaths with the collagen fibres oriented parallel to the myocytes and hence the myocytes themselves were wrapped with collagen in bundles. These sheaths are thought to prevent overextension of the myocytes, and ultimately muscle fibre bundles, linking them together so they can act in an antagonistic way transmitting forces. As in Haliotis kamtschat$k a n a$, the bundles diverge from connections with the sole of the pedal muscle as individual fibres, giving the appearance of a three dimensional mesh of muscle fibres. Similar to the previous findings in P. vulgata (Chapman 1958; Jones and Trueman 1970; Voltzow 1988), there was evidence of a very reduced circulatory system in the pedal muscle, the caveat being that the samples were perfusion fixed. As such, any blood vessels would likely collapse during fixation and consequently be difficult to detect. Nevertheless, 

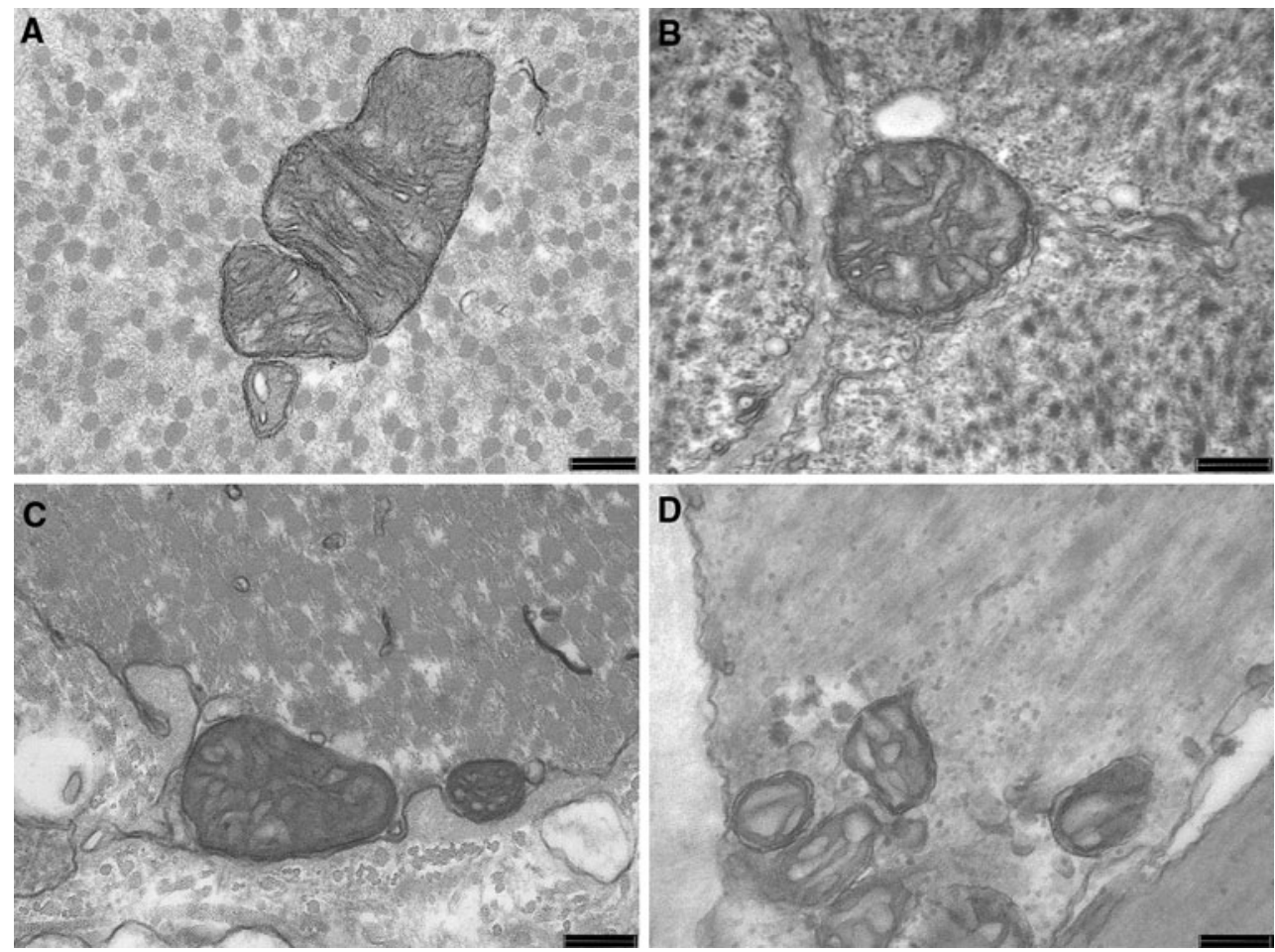

Fig. 4 Electron micrographs showing different morphologies of mitochondria in pedal muscles from: a Nacella concinna; b winter Cellana ornata $; \mathbf{c}$ summer Cellana ornata; $\mathbf{d}$ Cellana radiata. Note the packing

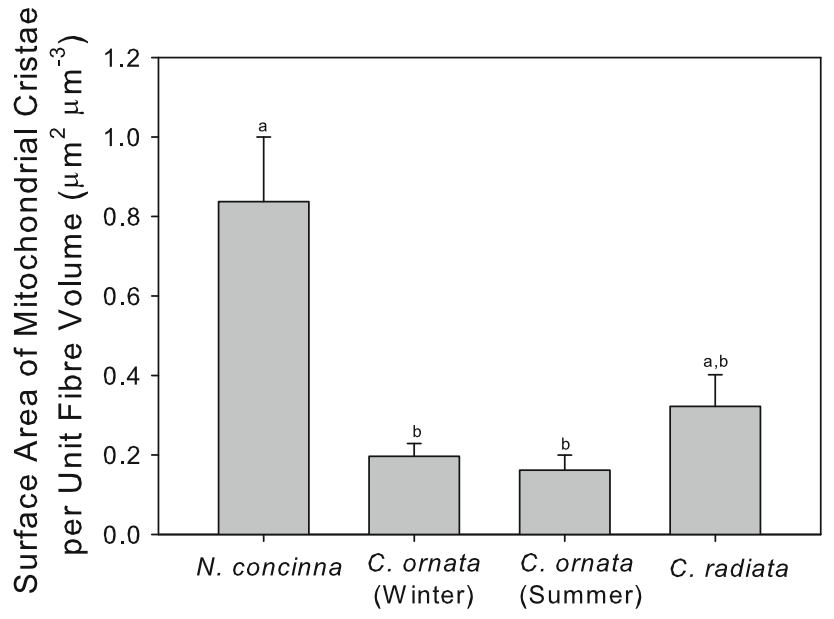

Fig. 5 Surface area of mitochondrial cristae per unit fibre volume (aerobic capacity) in pedal muscle of the limpets, Nacella concinna, Cellana ornata, and Cellana radiata. Values shown are mean $\pm \mathrm{SE}$. Different letters indicate significant differences between the groups

these findings support the hypothesis that the limpet pedal muscle functions not as a hydrostatic skeleton, that is "a fluid mechanism which in one way or another provides a means by which contractile elements can be antagonised" (Chapman 1958), but acts primarily by muscular antagonism, or as a muscular hydrostat (Kier and Smith 1985).

Limpet myocytes are 1-2 orders of magnitude smaller than vertebrate skeletal myocytes (Hoppeler et al. 1973; of cristae within each mitochondrion. Black scale bars represent $0.2 \mu \mathrm{m}$

Johnston et al. 1998; Mueller et al. 2009), but similar in size to brachiopod myocytes (Liothyrella spp.; Lurman et al. 2010). In the present study we found no significant differences among the species in the diameter of the myocytes, or evidence for changes in diameter as a result of seasonal acclimatization in $C$. ornata. This also agrees with data from New Zealand brachiopods (L. neozelanica) where we previously found no evidence of seasonal hypertrophy of myocytes (Lurman et al. 2010). The small size of the myocytes in the limpets may be related to the effective lack of a capillary system within the pedal muscle. In vertebrate muscle where myocytes typically have a diameter of 100-200 $\mu \mathrm{m}$ and are supplied by 1-2 capillaries (Hoppeler et al. 1973), the diffusion of oxygen and ions into the cells would be greatly inhibited without the capillaries, whereas smaller myocytes $(2-4 \mu \mathrm{m})$ would have the advantage of enhanced oxygen supply to myocytes via the phospholipid membranes and enhanced ion flux across the membrane during contraction.

Although spawning had no effect on heart rate (a proxy for metabolic rate, Marshall and McQuaid 1992; Santini et al. 1999) in Acmaea limatula (Segal 1956), spawning is known to have an effect on the biochemical composition of limpets (Blackmore 1969; Lawrence 1976). Lipids and glycogen are the primary energetic source for gametogenesis in gastropods (Gabbott 1976; Simpson 1982; Gabbott 1983). Previous studies examined the relationships between 
the biochemical composition of patellid (Blackmore 1969) and nacellid (Simpson 1982) limpets and their reproduction, and found an inverse relationship between the lipid and glycogen content of tissues such as the digestive gland and the lipid content of gametes, i.e. as the number of gametes increases, the glycogen content in the digestive gland decreases.

Gametogenesis in the Antarctic Nacella concinna is highly variable and coincides with the summer phytoplankton bloom (October-March). Annual spawning (NovemberJanuary) also coincides with the phytoplankton bloom (Powell 2001). The N. concinna used in our study were collected in early summer (November), i.e. shortly before spawning when gametogenesis typically peaks, or at the start of the spawning season and before the limpets had time to build up lipid stores for the winter (Powell 2001). This explains the low intracellular lipid droplet content. The large variation seen in the glycogen content in N. concinna (2-26\%) may reflect the degree to which some individuals were active and/or supplemented gametogenesis (Gabbott 1976, 1983). Similarly, the New Zealand C. ornata sampled in winter had a greater density of lipid droplets and glycogen granules in the pedal muscle, built up over the preceding months during the resting phase of reproduction (Dunmore and Schiel 2000) and spared by a seasonal decrease in the respiration rate (as seen in N. concinna, Fraser et al. 2002). In late summer and early autumn (January-March) the respiration rate increases in C. ornata spawn (Dunmore and Schiel 2000), and as a consequence the densities of lipid droplet and glycogen granule were depleted. C. radiata from India develop gonads from February to May, and the spawning begins in June and extends to February or March (Rao 1973). Thus, the 9-10 month spawning period interspersed by gonad development in the tropics results in "chronically" low levels of lipid droplet and glycogen granule stores in the pedal muscle because there is no need to build up stores for winter. This shows that the lipid droplet density was low for all the species in our study. In the sub-Antarctic limpet Nacella macquariensis, total lipid content in the pedal muscle was also very low varying between 2.6 and $4.8 \%$ over a year which is characteristic of levels of structural lipids, and suggests that, as found in the present study, the pedal muscle is not a major storage site for lipids or glycogen (Simpson 1982).

The cellular distribution of mitochondria was predominantly (i.e. $63-84 \%$ ) subsarcolemmal. While not as substantial as the $100 \%$ of mitochondria that were subsarcolemmal in brachiopods (Lurman unpubl data), this nevertheless gives us clues to the oxygen conditions within the cell. The predominance of subsarcolemmal positioning would aid the function by having the mitochondria as close to the oxygen source as possible and potentially acting as oxygen conduits between the myocytes, enhancing diffu- sion from the outer to inner layers of a muscle bundle (Sidell 1983).

We previously reported significantly higher volume densities of mitochondria in the Antarctic brachiopod Liothyrella uva when compared to its temperate congener, L. neozelanica (Lurman et al. 2010). Comparing the three limpets in the present study, we again see that the Antarctic species has significantly more mitochondria than the temperate and tropical species. This reflects previous observations of mitochondrial proliferation in sub-Arctic compared to temperate invertebrates (Sommer and Pörtner 2002). A reduction in temperature leads to a reduction in mitochondrial capacity and in the diffusion efficiency of substrates in and metabolic products out of the mitochondria (Guderley 2004b; Kinsey et al. 2007). Furthermore, mitochondrial efficiency may be reduced in the cold and proliferation is one aspect of the compensatory mechanism that maintains the aerobic scope in cold-active species (Johnston et al. 1998; Pörtner et al. 2000).

The temperature difference for $C$. ornata between summer and winter was $8^{\circ} \mathrm{C}$. This is relatively small when compared to species such as carp (Carassius carassius) which experience a more extreme temperature range of $\simeq 25^{\circ} \mathrm{C}$ (Kilarski et al. 1996). This potentially explains why the volume density of mitochondria was not significantly altered by seasonal acclimatization. The cristae surface density was, however, significantly lower in summer. This complements previous work with the New Zealand brachiopod L. neozelanica, where, as mentioned above, no difference in the volume density of mitochondria was seen after seasonal acclimatization, but the surface density of mitochondrial cristae was significantly increased after winter acclimatization (Lurman et al. 2010). A similar effect of acclimation to elevated temperature was observed in Antarctic limpets, $N$. concinna. This resulted in a significant decrease in the surface density of mitochondrial cristae in the three populations, with the greatest decrease seen in $N$. concinna from South Georgia which experiences the warmest and most variable temperatures (Morley et al. 2009). A pattern is emerging with alterations in the cristae surface density being the most common adaptation to short-term acute or seasonal changes in temperature in these invertebrates. Changes in the surface density of mitochondrial cristae as a result of seasonal acclimatization may be a more efficient way of up-regulating the reactive surface for oxidative phosphorylation in individual mitochondria, eliminating some of the costs associated with making mitochondria de novo, and also preventing loss in the volume of the contractile apparatus (see Lurman et al. 2010 for a more in-depth discussion). This might be of particular importance in N. concinna and other Antarctic marine invertebrates, where protein synthesis rates are considerably slower (Fraser et al. 2007), yet they must still be able to 
adjust their systems to respond to the seasonal rate of warming. Experiments are in progress on invertebrates like carp that experience larger temperature ranges and they may shed more light on this novel mechanism.

There was no significant change in the aerobic scope $\left(\mathrm{Sv}_{(\mathrm{im}, \mathrm{f})}\right)$ as a result of seasonal acclimatization in C. ornata. Similarly, no change in aerobic scope was seen previously in L. neozelanica as a result of acclimatization (Lurman et al. 2010). Both species are less active during winter (Boyden and Zeldis 1979; Lamare unpubl data). This strategy would reduce metabolic demands and as a consequence, mitochondrial proliferation, which may bear an unnecessarily high cost, would be avoided. In fish, coldinactive species such as carp reduce their energetic needs during cold acclimation as reflected in the reduced proton leak rate (Jastroch et al. 2007). On the other hand, coldactive fishes increase mitochondrial volume density (Johnston et al. 1998) to overcome increased inefficiencies, e.g. proton leak (Guderley 2004a; Mark et al. 2006).

It is perhaps surprising that the tropical $C$. radiata differed neither in the volume density of mitochondria nor the surface density of mitochondrial cristae compared to the temperate $C$. ornata. The mitochondrial proliferation in the cold paradigm would predict that at least the mitochondrial volume density would be further reduced, and it is not clear why this is not the case. The mitochondrial volume densities are very low in limpets (1-2\%) compared to vertebrates, which are typically an order of greater magnitude. Although $C$. radiata and limpets in general have a low metabolic rate (Rao 1980), there is still a minimal energy requirement that will set the lower limit for the number of mitochondria required by a tissue. This limit may lie between 1 and $2 \%$ as exemplified here. However, a lot more work needs to be done to test this hypothesis.

A comparison of limpet species from different thermal habitats shows that long-term adaptation to low temperatures results in an increase in the volume density of mitochondria. Antarctic limpets had an approximately fourfold higher volume density of mitochondria in their pedal muscle compared to temperate and tropical limpets. What is novel is that unlike ectothermic vertebrates, changes in surface density of mitochondrial cristae appear to be the predominant mechanism for invertebrates to compensate for temperature-induced reductions in mitochondrial activity during short-term acute or seasonal temperature change. Given the large variation in energetic stores, i.e. lipid and glycogen in the pedal muscle as a result of seasonal acclimatization and thermal niche, like Parry (1984), we wonder whether the differences are directly due to thermal acclimatization and adaptation of the metabolic rate or to changes in growth rates and reproductive cycles. Clearly, further experiments are needed to disentangle these confounding variables before a concrete conclusion can be drawn.
Acknowledgments Marianne Hofstetter and Kerstin Meyer are thanked for their assistance during histological preparation. Ruth Vock, Hans Hoppeler, Jean-Michel Weber and Daniela Lurman-Lange are thanked for insightful discussions. This project was financed in part by the ESF ThermAdapt short visit grant (2148) awarded to GL, a Society for Experimental Biology travel grant awarded to GL, a TransAntarctic Association grant awarded to SM, the University of Bern, and funding from the Natural Environment Research Council via the British Antarctic Survey BIOREACH project in the BIOFLAME programme.

\section{References}

Barry RJC, Munday KA (1959) Carbohydrate levels in Patella. J Mar Biol Assoc UK 38:81-95

Blackmore DT (1969) Studies of Patella vulgata L. II. Seasonal variation in biochemical composition. J Exp Mar Biol Ecol 3:231-245

Boyden CR, Zeldis JR (1979) Preliminary observations using an attached microphonic sensor to study feeding behaviour of an intertidal limpet. Estuar Coast Mar Sci 9:759-769

Chapman G (1958) The hydrostatic skeleton in the invertebrates. Biol Rev 33:338-371

Dunmore RA, Schiel DR (2000) Reproduction in the intertidal limpet Cellana ornata in southern New Zealand. NZ J Mar Freshwater Res 34:653-660

Egginton S, Sidell BD (1989) Thermal acclimation induces adaptive changes in subcellular structure of fish skeletal muscle. Am J Physiol 256:R1-R9

Ellis EA (2002) New embedding formulations using Quetol 651. Microsc Microanal 8:884-885

Fraser KPP, Clarke A, Peck LS (2002) Feast and famine in Antarctica: seasonal physiology in the limpet Nacella concinna. Mar Ecol Prog Ser 242:169-177

Fraser KPP, Clarke A, Peck LS (2007) Growth in the slow lane: protein metabolism in the Antarctic limpet Nacella concinna (Strebel 1908). J Exp Biol 210:2691-2699

Gabbott PA (1976) Energy metabolism. In: Bayne BL (ed) Marine mussels, their ecology and physiology. Cambridge University Press, Cambridge, pp 293-356

Gabbott PA (1983) Developmental and seasonal metabolic activities in marine molluscs. In: Hochachka PW (ed) The mollusca. Academic Press, New York, pp 165-217

Guderley H (2004a) Metabolic responses to low temperature in fish muscle. Biol Rev 79:409-427

Guderley H (2004b) Locomotor performance and muscle metabolic capacities: impact of temperature and energetic status. Comp Biochem Physiol 139B:371-382

Hoppeler H, Lüthi P, Claassen H, Weibel E, Howald H (1973) The ultrastructure of the normal human skeletal muscle. Eur J Physiol 344:217-232

Jastroch M, Buckingham J, Helwig M, Klingenspor M, Brand M (2007) Functional characterisation of UCP1 in the common carp: Uncoupling activity in liver mitochondria and cold-induced expression in the brain. J Comp Physiol B 177:743-752

Johnston IA, Calvo J, Guderley H, Fernandez D, Palmer L (1998) Latitudinal variation in the abundance and oxidative capacities of muscle mitochondria in perciform fishes. J Exp Biol 201:1-12

Jones HD, Trueman ER (1970) Locomotion of the Limpet, Patella vulgata L. J Exp Biol 52:201-216

Kier WM, Smith KK (1985) Tongues, tentacles and trunks: the biomechanics of movement in muscular-hydrostats. Zool J Linnean Soc 83:307-324

Kilarski WM, Romek M, Kozlowska M, Gorlich A (1996) Short-term thermal acclimation induces adaptive changes in the inner 
mitochondrial membranes of fish skeletal muscle. J Fish Biol 49:1280-1290

Kinsey ST, Hardy KM, Locke BR (2007) The long and winding road: influences of intracellular metabolite diffusion on cellular organization and metabolism in skeletal muscle. J Exp Biol 210:35053512

Lawrence JM (1976) Patterns of lipid storage in post-metamorphic marine invertebrates. Am Zool 16:747-762

Lurman GJ, Blaser T, Lamare M, Peck LS, Morley SA (2010) Mitochondrial plasticity in brachiopod (Liothyrella spp.) smooth adductor muscle as a result of season and latitude. Mar Biol 157:907-913

Mark FC, Lucassen M, Portner HO (2006) Thermal sensitivity of uncoupling protein expression in polar and temperate fish. Comp Biochem Physiol 1D:365-374

Marshall DJ, McQuaid CD (1992) Relationship between heart rate and oxygen consumption in the intertidal limpets Patella granularis and Siphonaria oculus. Comp Biochem Physiol 103A:297-300

Morley SA, Lurman G, Skepper JN, Pörtner H-O, Peck LS (2009) Thermal plasticity of mitochondria: a latitudinal comparison between Southern Ocean molluscs. Comp Biochem Physiol 152A:423-430

Mueller M, Breil F, Vogt M, Steiner R, Lippuner K, Popp A, Klossner S, Hoppeler H, Däpp C (2009) Different response to eccentric and concentric training in older men and women. Eur J Appl Physiol 107:145-153

Parry GD (1984) The effect of food deprivation on seasonal changes in the metabolic rate of the limpet, Cellana tramoserica. Comp Biochem Physiol 77A:663-668

Plagényi EE, Branch GM (2000) Does the limpet Patella cochlear fertilize its own algal garden? Mar Ecol Prog Ser 194:113-122

Pörtner HO, van Dijk PLM, Hardewig I, Sommer A (2000) Levels of metabolic cold adaptation: tradeoffs in eurythermal and stenothermal ectotherms. In: Davison W, Williams CH (eds) Antarctic Ecosystems: models for wider ecological understanding. Caxton Press, Christchurch, pp 109-122

Powell DK (2001) The Reproductive ecology of Antarctic free-spawning molluscs. University of Southampton, Southampton

Rao MB (1973) Sex phenomenon and reproductive cycle in the limpet Cellana radiata (Born) (Gastropoda: Prosobranchia). J Exp Mar Biol Ecol 12:263-278
Rao MB (1980) Studies on the oxygen consumption of a tropical intertidal limpet Cellana radiata (Born): effect of body size and tidal rhythm. Hydrobiol 71:175-179

Sänger A (1993) Limits to the acclimation of fish muscle. Rev Fish Biol Fisher 3:1-15

Santini G, De Pirro M, Chelazzi G (1999) In situ and laboratory assessment of heart rate in a mediterranean limpet using a noninvasive technique. Physiol Biochem Zool 72:198-204

Segal E (1956) Microgeographic variation as thermal acclimation in an intertidal mollusc. Biol Bull 111:129-152

Sidell BD (1983) Cellular acclimatisation to environmental change by quantitative alterations in enzymes and organelles. In: Cossins AR, Sheterline P (eds) Cellular acclimatisation to environmental change. Cambridge University Press, London, pp 103-120

Simpson RD (1982) Reproduction and lipids in the sub-Antarctic limpet Nacella (Patinigera) macquariensis Finlay, 1927. J Exp Mar Biol Ecol 56:33-48

Sommer AM, Pörtner HO (2002) Metabolic cold adaptation in the lugworm Arenicola marina: comparison of a North Sea and a White Sea population. Mar Ecol Prog Ser 240:171-182

St-Pierre J, Charest PM, Guderley H (1998) Relative contribution of quantitative and qualitative changes in mitochondria to metabolic compensation during seasonal acclimatisation of rainbow trout Oncorhynchus mykiss. J Exp Biol 201:2961-2970

Stützel R (1984) Anatomische und Ultrastrukturelle Untersuchungen an der Napfschnecke Patella L. unter besonderer Berücksichtigung der Anpassung an den Lebensraum. Scheweizerbart, Stuttgart

Voltzow J (1988) The organization of limpet pedal musculature and its evolutionary implications for the Gastropoda. Malacol Rev 4:273-283

Voltzow J (1990) The functional morphology of the pedal musculature of the marine gastropods Busycon contrarium and Haliotis kamtschatkana. Veliger 33:1-19

Voltzow J (1994) Gastropoda: Prosobranchia. In: Harrison FW, Kohn AJ (eds) Microscopic anatomy of invertebrates, volume 5: Mollusca. Wiley-Liss, New York, pp 111-252

Weibel ER (1979) Stereological methods. Academic Press, London 